\title{
RANCANG BANGUN APLIKASI MOBILE EDUKASI MENGENAI PARENTING SKILLS BAGI ORANG TUA BERBASIS ANDROID DENGAN MENGGUNAKAN BAHASA PEMROGRAMAN JAVA ANDROID
}

\author{
Agung Ramadhanu'), Rahmatul Husna Arsyah ${ }^{2)}$, Neni Sri Wahyuni Nengsi ${ }^{3),}$ Nurhaliza ${ }^{4)}$ \\ ${ }^{1}$ Fakultas Ilmu Komputer, Universitas Putra Indonesia "YPTK" Padang, Jl. Raya Lubuk Begalung \\ email: agung_ramadhanu@upiyptk.ac.id \\ ${ }^{2}$ Fakultas Keguruan dan Ilmu Pendidikan, Universitas Putra Indonesia "YPTK” Padang, Jl. Raya Lubuk \\ Begalung \\ email: rahmatulhusna arsyah@upiyptk.ac.id \\ ${ }^{3}$ Fakultas Ekonomi dan Bisnis, Universitas Putra Indonesia "YPTK" Padang, Jl. Raya Lubuk Begalung \\ email: nenisriwahyuni nengsi@upiyptk.ac.id \\ ${ }^{4}$ Fakultas Ilmu Komputer, Universitas Putra Indonesia "YPTK” Padang, Jl. Raya Lubuk Begalung \\ email: nurhaliza0910@gmail.com
}

\begin{abstract}
Parenting adalah proses interaksi berkelanjutan antara orang tua dan anak-anak mereka yang meliputi aktivitas-aktivitas seperti memberi makan, memberi petunjuk, dan melindungi anakanak ketika mereka tumbuh. Aktivitas-aktivitas parenting biasanya terjadi dalam lingkungan keluarga, namun parenting tidak terbatas hanya pada mereka yang melahirkan anak. Tanggung jawab parenting juga dilakukan oleh pihak-pihak lain dalam masyarakat,seperti para guru di sekolah, pembantu rumah tangga, perawat bayi (baby sitter), serta media masa (Televisi, surat kabar, dan majalah). Kendati demikian,orang tua adalah pihak yang paling bertanggung jawab dalam mengasihi dan memperhatikan anak-anak serta menolong mereka tumbuh. Jadi Parenting skill merupakan suatu keterampilan orang tua dalam mendidik atau mengasuh anaknya agar menjadi pribadi yang lebih baik. Dan dengan adanya suatu aplikasi parenting skills akan dapat memberikan pemahaman dan mempermudah para orang tua dalam mendidik anaknya dengan baik.
\end{abstract}

Keywords: Parenting Skill, Android, Android Studio.

\section{PENDAHULUAN}

Anak merupakan anugerah yang diberikan Allah swt kepada para orang tua,para orang tua harus bisa mendidik anaknya agar tumbuh menjadi anak yang baik. Menjadi orangtua yang baik berarti memberi kepada anak-anak kita semua cinta yang kita miliki dan semua nilainilai positif untuk membuat mereka menjadi orang yang bertanggung jawab,sensitif,memiliki toleransi,bisa mengekspresikan perasaan mereka dan dapat menyelesaikan masalah.

Parenting adalah proses interaksi berkelanjutan antara orang tua dan anakanak mereka yang meliputi aktivitasaktivitas seperti memberi makan,memberi petunjuk, dan melindungi anak-anak ketika mereka tumbuh. Aktivitas-aktivitas parenting biasanya terjadi dalam lingkungan keluarga, namun parenting tidak terbatas hanya pada mereka yang melahirkan anak. Tanggung jawab parenting juga dilakukan oleh pihak-pihak lain dalam masyarakat,seperti para guru di sekolah, pembantu rumah tangga, perawat bayi (baby sitter), dan bahkan teman-teman si anak, serta media masa (TV, surat kabar, dan majalah). Kendati demikian,orang tua adalah pihak yang paling bertanggung jawab dalam mengasihi dan memperhatikan anak-anak serta menolong mereka bertumbuh. Jadi Parenting skill merupakan suatu 
ketrampilan orang tua dalam mendidik atau mengasuh anaknya agar menjadi pribadi yang lebih baik.

Beberapa definisi tentang pengasuhan menunjukkan bahwa konsep pengasuhan mencakup beberapa pengertian pokok, antara lain: (1) pengasuhan bertujuan untuk mendorong pertumbuhan dan perkembangan anak secara optimal, baik secara fisik, mental maupun sosial, (2) pengasuhan merupakan sebuah proses interaksi yang terus menerus antara orang tua dengan anak, (3)pengasuhan adalah sebuah proses sosialisasi, (4) sebagai sebuah proses interaksi dan sosialisasi. proses pengasuhan tidak bisa dilepaskan dari sosial budaya dimana anak dibesarkan.

Dan ada satu alternatif untuk dapat memberikan pemahaman bagi orang tua dalam mendidik anaknya,yaitu sebuah aplikasi parenting skills berbasis android. Oleh karena itu penulis ingin merancang sebuah aplikasi yang bisa mempermudah para orang tua menambah pemahaman dalam mendidik anaknya dengan judul "Rancang Bangun Aplikasi Mobile Edukasi Mengenai Parenting Skills Bagi Orang Tua Berbasis Android Dengan Menggunakan Bahasa Pemrograman Java Android"

\section{METODE PENELITIAN}

Untuk mencapai keakuratan dan ketelitian data serta informasi dalam penelitian ini maka pengumpulan data dilakukan dengan 3 cara :

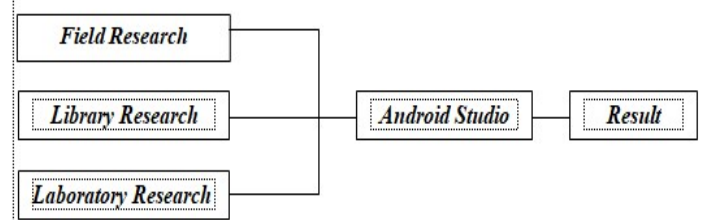

\section{Penelitian Lapangan (Field Research)}

Penelitian ini langsung dilakukan ke lapangan yaitu mengadakan interview dengan mengajukan daftar pertanyaan dan meminta beberapa bentuk laporan yang diharapkan dapat berdasarkan kenyataan yang ada dan lebih objektif.

\section{Penelitian Kepustakaan (Library} Research)

Penelitian yang dilakukan melalui literatur-literatur yang ada berkaitan dengan judul laporan studi akhir ini. Untuk mencari informasi dalam menyusun teori-teori yang didapat baik secara global, baik secara detail yang berhubungan dengan pembahasan, sehingga terjadi perpaduan yang kompleks antara satu dengan yang lainnya.

\section{Penelitian} (Laboratory Research)

Penelitian yang dilakukan dalam pembuatan program yang dirancang dengan menggunakan data-data valid maupun tidak valid yang dapat membantu proses pembelajaran terhadap anak di usia dini., dalam hal ini penulis mempergunakan perangkat komputer dengan spesifikasi sebagai berikut :

a. Perangkat keras yang dipergunakan

- Intel Celeron DualCore N3050,1.60 $\mathrm{GHz}$

- RAM 4 GB DDR3

- Harddisk 500 GB 5400 RPM

b. Perangkat lunak yang dipergunakan

- Sistem Operasi Windows 8.1 Enterprise 32-bit

- Android Studio 32-bit

- Android SDK

- JDK for windows 8 update 181

- Microsoft Office 2007

- CorelDRAW X7

\section{HASIL DAN PEMBAHASAN}

Analisa sistem dapat didefinisikan sebagai penguraian dari suatu system informasi yang utuh ke dalam bagian-bagian komponennya dengan maksud untuk mengidentifikasikan dan mengevaluasi permasalahan-permasalahan,kesempatankesempatan,hambatan-hambatan yang 
terjadi dan kebutuhan-kebutuhan yang diharapkan sehingga dapat diusulkan perbaikan-perbaikannya.

1. Analisa Kebutuhan

$\begin{array}{ll}\text { a. Analisa } & \text { Kebutuhan } \\ \text { Fungsional } & \end{array}$

Kebutuhan fungsional (functional requirement)adalah jenis kebutuhan yang berisi proses-proses apa saja yang nantinya dilakukan oleh sistem. Kebutuhan fungsional juga berisi informasi-informasi apa saja yang harus ada dan dihasilkan oleh aplikasi ini nantinya, diantaranya adalah sebagai berikut :

1) Dalam aplikasi mobile edukasi ini terdapat menu utama yang terdiri dari 7 tombol. Yaitu Dashboard, Materi, Tips \& Trik, Aktivitas dan Profil.

2) Masing-masing menu berisi materi yang ditampilkan berupa pemahaman seputar cara mendidik anak dengan baik.

b. Analisa kebutuhan non fungsional

Kebutuhan non fungsional (nonfunctional requirement) adalah tipe kebutuhan yang meliputi kebutuhan perangkat keras (hardware), kebutuhan perangkat lunak (software), dan kebutuhan sumber daya manusia(brainware).

1) Analisa kebutuhan perangkat keras (hardware)

Analisa kebutuhan perangkat keras bertujuan untuk mengetahui secara tepat perangkat keras yang dibutuhkan. Adapun hardware yang digunakan dalam proses pembuatan adalah sebuah laptop dengan spesifikasi sebagai berikut :

a) Processor Intel Celeron DualCore N3050,1.60 $\mathrm{GHz}$

b) RAM 4 GB DDR3

c) Harddisk 500 GB 5400 RPM

Adapun Hardware yang digunakan dalam penerapan adalahsebuah smartphone dengan spesifikasi sebagai berikut :

a) Samsung Galaxy J7 Prime

b) RAM 3 GB

c) Dimensi $151.7 \times 75.0$ x $8.0 \mathrm{~mm}$

2) Analisa kebutuhan perangkat lunak (software)

Perangkat lunak

merupakan perangkat yang berfungsi melakukan pengerjaan dalam data processing system untuk mendukung bekerjanya sistemsistem komputer. Kebutuhan yang dibutuhkan adalah Sistem Operasi, serta kebutuhankebutuhan lainnya bisa didapatkan secara gratis. Adapun software yang dibutuhkan untuk pembuatan aplikasi mobile edukasi ini adalah sebagai berikut :

a) SO Microsoft Windows 7

b) Android Studio 32-bit

c) Android SDK

d) JDK for windows 8 update 181

e) Microsoft Office 2007

f) Genymotion Emulator 2.12 .2

g) CorelDRAW X7

\section{Perancangan}

Perancangan adalah penggambaran, perencanaan dan pembuatan sketsa atau pengaturan dari beberapa elemen yang 
terpisah ke dalam satu kesatuan yang utuh dan berfungsi (Syifaun Nafisah, 2003 : 2). Perancangan sistem dapat dirancang dalam bentuk bagan alir sistem (system flowchart), yang merupakan alat bentuk grafik yang dapat digunakan untuk menunjukan urutan-urutan proses dari sistem.

Kenneth dan Jane (2006:G12) menjelaskan bahwa perancangan sistem adalah kegiatan merancang detil dan rincian dari sistem yang akan dibuat sehingga sistem tersebut sesuai dengan requirement yang sudah ditetapkan dalam tahap analisa sistem. Lebih lanjut O'Brien dan Marakas (2009:639) menjelaskan bahwa perancangan sistem adalah sebuah kegiatan merancang dan menentukan cara mengolah sistem informasi dari hasil

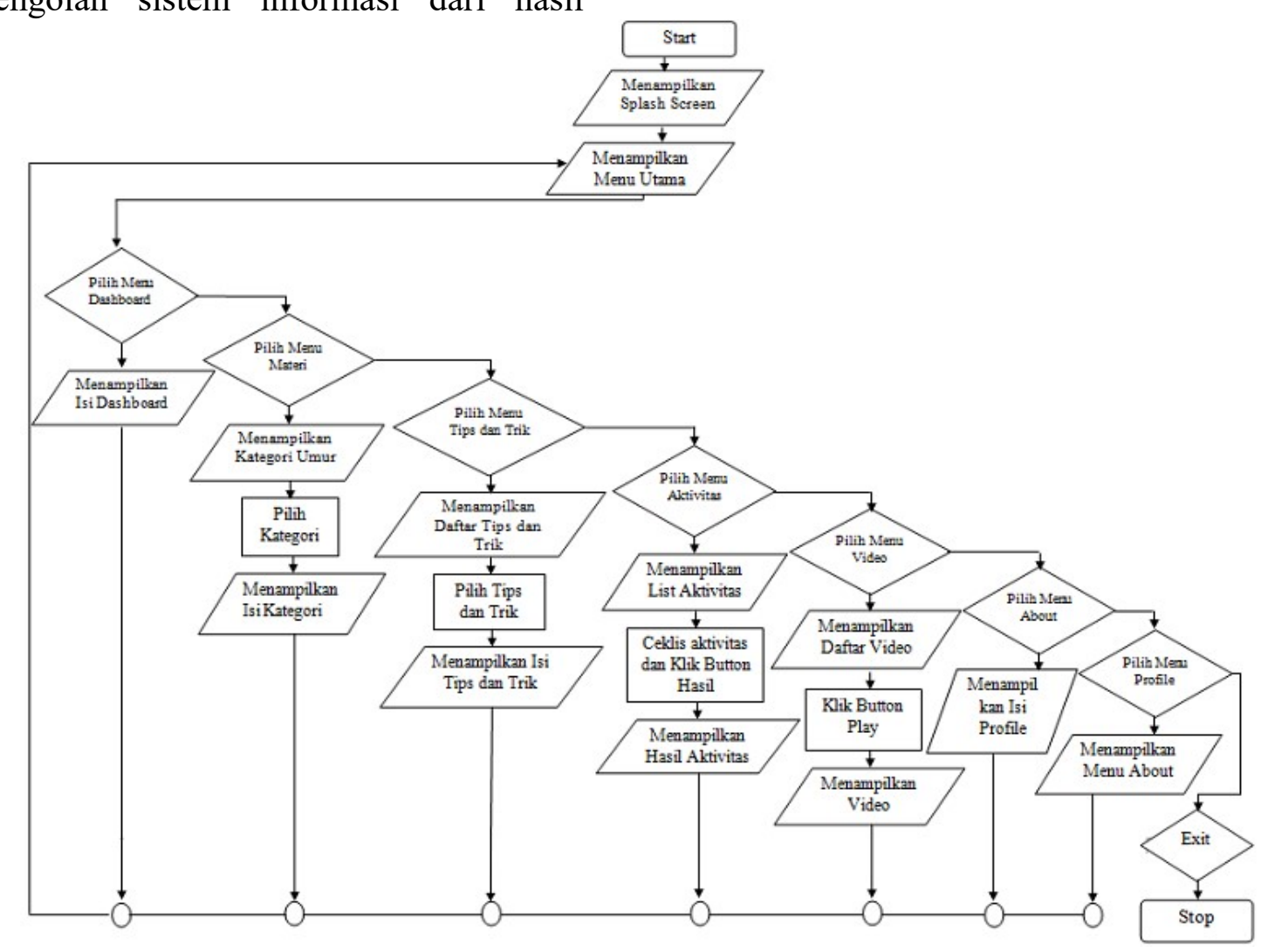

\subsection{Implementasi Sistem}

Tahap implementasi sistem merupakan salah satu tahap dalam daur hidup pengembangan sistem, dimana tahap ini merupakan tahap meletakkan sistem informasi supaya siap untuk dipakai. Dalam tahap ini berlangsung beberapa analisa sistem sehingga dapat memenuhi kebutuhan dari pengguna termasuk diantaranya perancangan user interface, data dan aktivitas proses.

\subsubsection{Flowchart Diagram}

Flowchart Diagram merupakan suatu bagan yang menggambarkan atau merepresentasikan prosedur untuk menyelesaikan masalah. Dengan kata lain, flowchart dapat disebut sebagai gambaran awal bagaimana program nantinya akan berjalan.

Berikut ini adalahFlowchart Diagramdari Aplikasi Parenting Skill, dapat dilihat Gambar 4.1 berikut: 
implementasi perlu dibuat terlebih dahulu. Rencana implementasi ini dimaksudkan untuk mengatur biaya serta waktu yang dibutuhkan selama tahap implementasi.

\subsection{Pengujian Sistem}

Ada dua cara yang dapat dilakukan untuk menjalankan aplikasi ini, yang pertama menggunakan emulator dan yang kedua menjalankan langsung pada smartphone android. Untuk menjalankan aplikasi ini penulis memilih untuk menjalankan secara langsung pada smartphone android. Berikut adalah tampilan aplikasi pada smartphone android

\subsubsection{Tampilan Splash Screen}

Splash Screen merupakan tampilan pada saat pertama kali aplikasi dibuka.

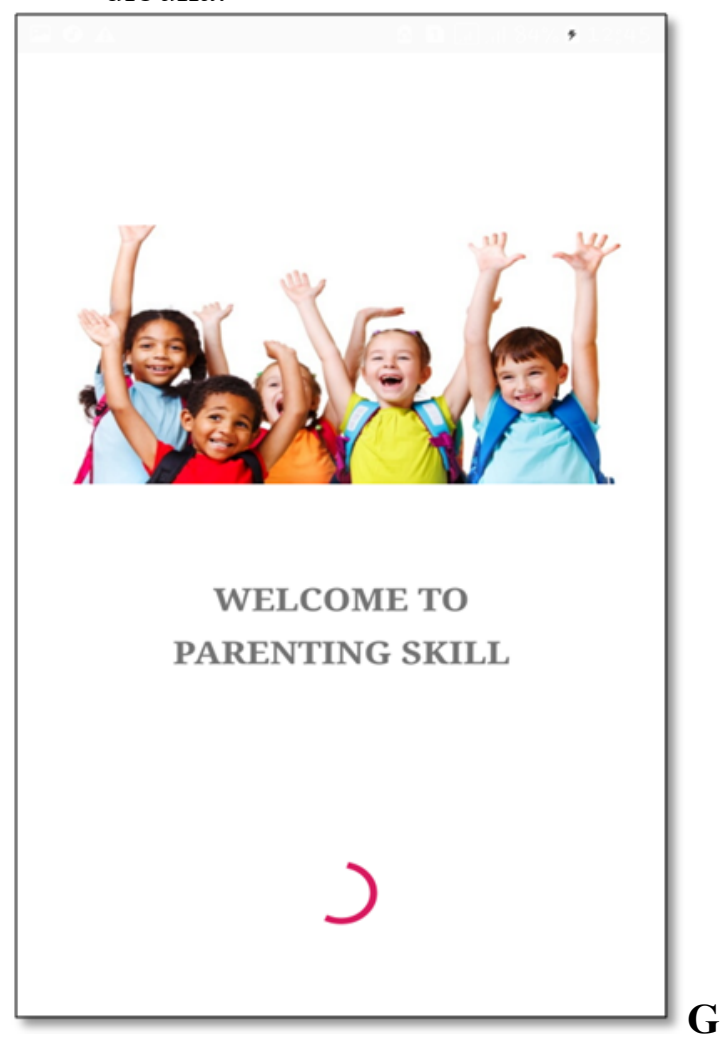

ambar 4.2 Tampilan Splash Screen

\subsubsection{Tampilan Menu Dashboard}

Tampilan Menu Dashboard adalah tampilan yang tampil setelah Splash Screen.

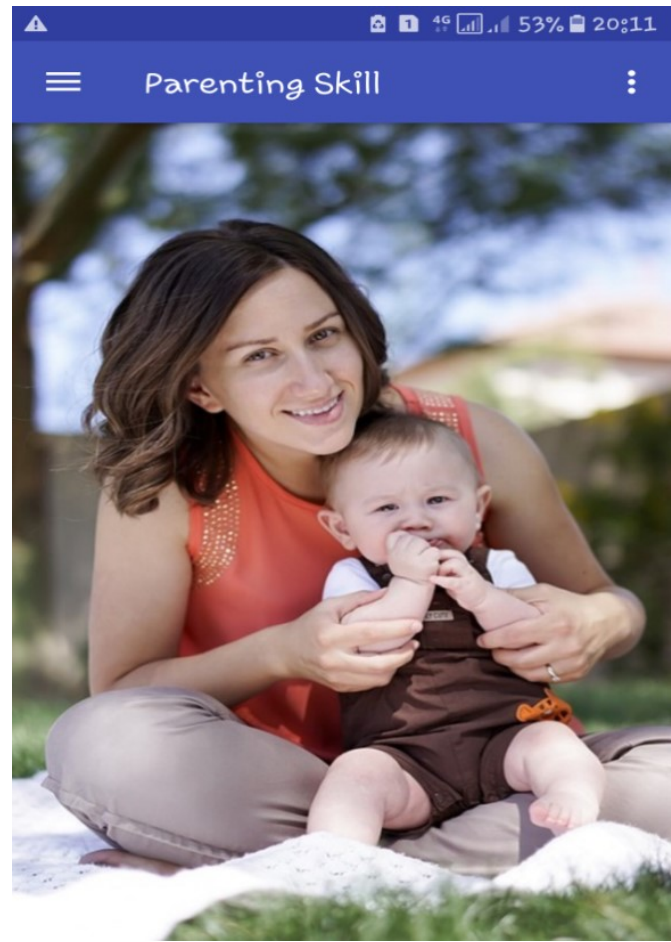

Gambar 4.3 Tampilan Menu Dashboard

\subsubsection{Tampilan Menu Utama}

Tampilan Menu Utama merupakan tampilan yang terdiri dari menumenu apa saja yang bisa ditampilkan, seperti menu Dashboard, Materi, Tips \& Trik, Aktivitas, Video dan About.

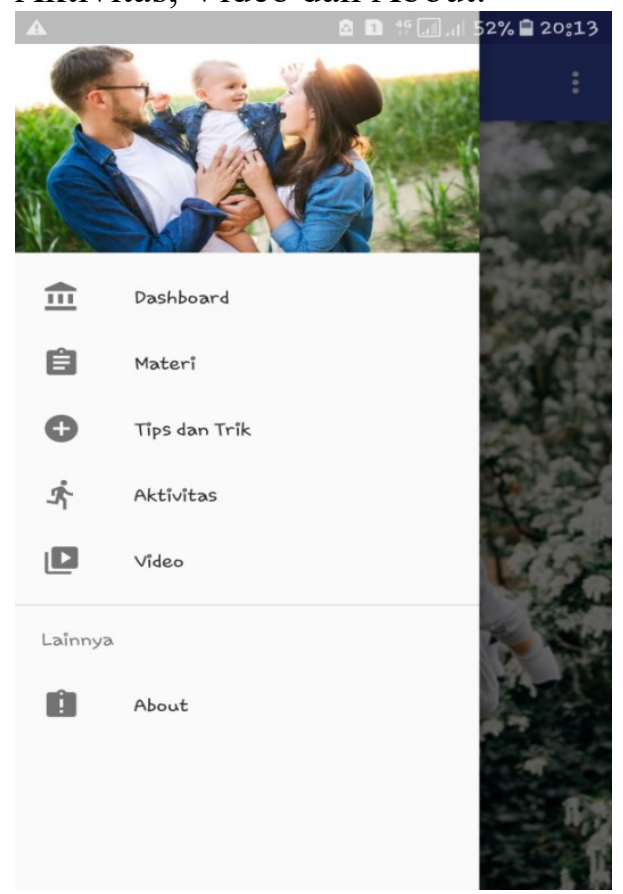

Gambar 4.4 Tampilan Menu Utama 


\subsubsection{Tampilan Menu Materi}

Merupakan tampilan menu yang berisi tentang materi-materi yang mencakup tentang parenting skill. Seperti materi pengasuhan, materi untuk katgori umur 0-6 Tahun, umur 7-14 Tahun dan 15-21 Tahun.

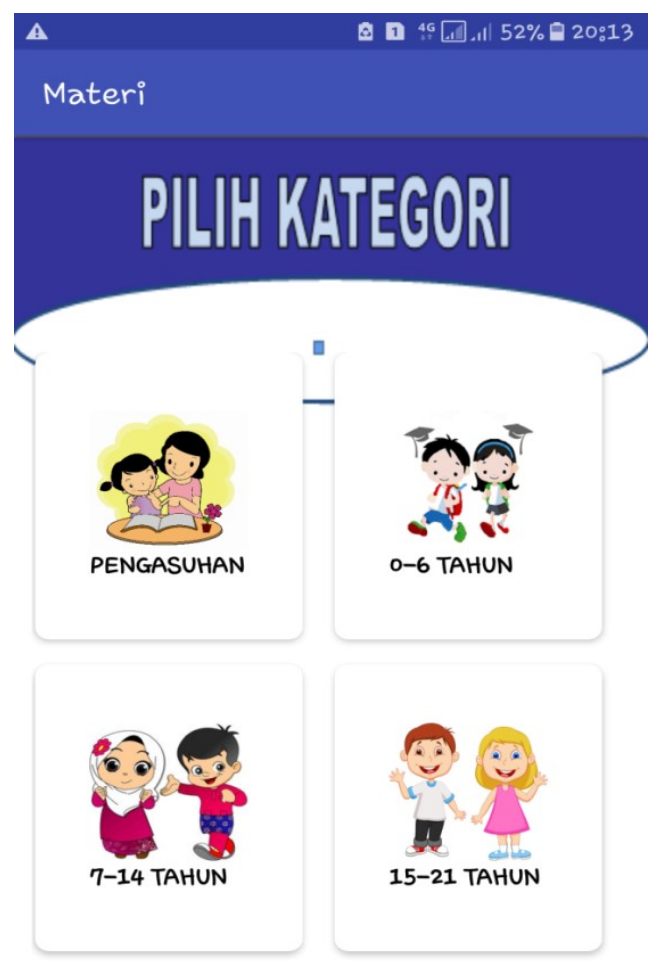

\section{Gambar 4.5 Tampilan Menu Materi}

\subsubsection{Tampilan Materi Pengasuhan}

Merupakan salah satu isi dari menu materi yang menjelaskan tentang bagaimana suatu pengasuhan yang baik / bagaimana mendidik anak dengan baik.

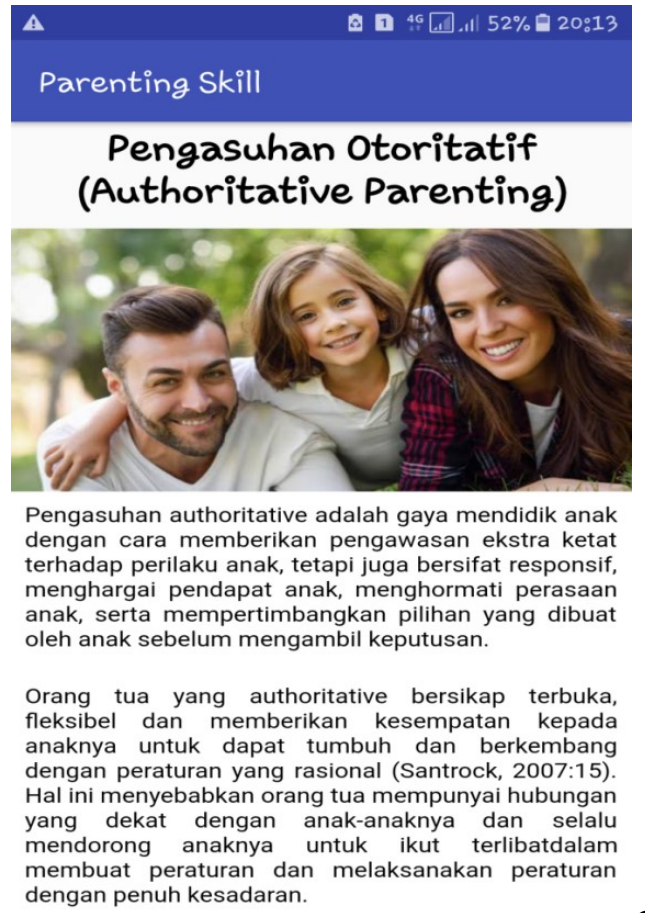

Gam

\section{bar 4.6 Tampilan Materi Pengasuhan}

\subsubsection{Tampilan Menu Tips dan Trik}

Tampilan Menu Tips dan Trik merupakan menu yang berisi tentang beberapa cara atau Tips dan Trik untuk orang tua dalam mengatasi suatu masalah yang terjadi pada anaknya.

Tips \& Trik
Cara Mendidik Anak agar Cerdas Menyeluruh
Cara Mendidik Anak yang Keras Kepala
Cara Meningkatkan Keberanian Pada Anak
Cara Menghilangkan Stress Pada Anak
Cara Menyikapi Anak yang Hiperaktif
Cara Mengatasi Anak Broken Home
Cara Mendidik Anak yang Suka Membantah
Cara Menghadapi Anak tidak Mau Sekolah
Cara Mendidik Anak Down Sindrom
Cara Menghilangkan Trauma Psikis pada Anak
Cara Agr Rutinitas Anak Tidak Membosankan

Gambar 4.7 Tampilan Menu Tips dan Trik 


\subsubsection{Tampilan Tips dan Trik 1}

Tampilan ini merupakan salah satu bentuk tampilan dari Menu Tips dan Trik. Disini isi Tips dan Trik yang akan ditampilkan adalah tentang Cara Mendidik Anak agar Cerda Menyeluruh.
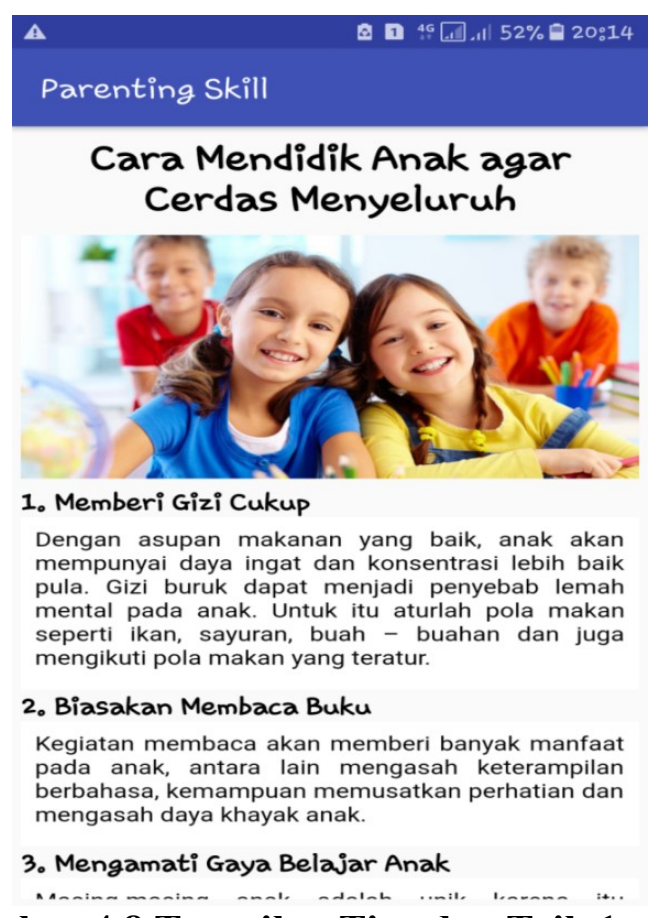

Gambar 4.8 Tampilan Tips dan Trik 1

\subsubsection{Tampilan Menu Aktivitas}

Merupakan tampilan yang berisi tentang aktivitas-aktivitas apa saja yang seharusnya dilakukan orang tua bersama anaknya untuk menguatkan ikatan batin antara orang tua dan anak.

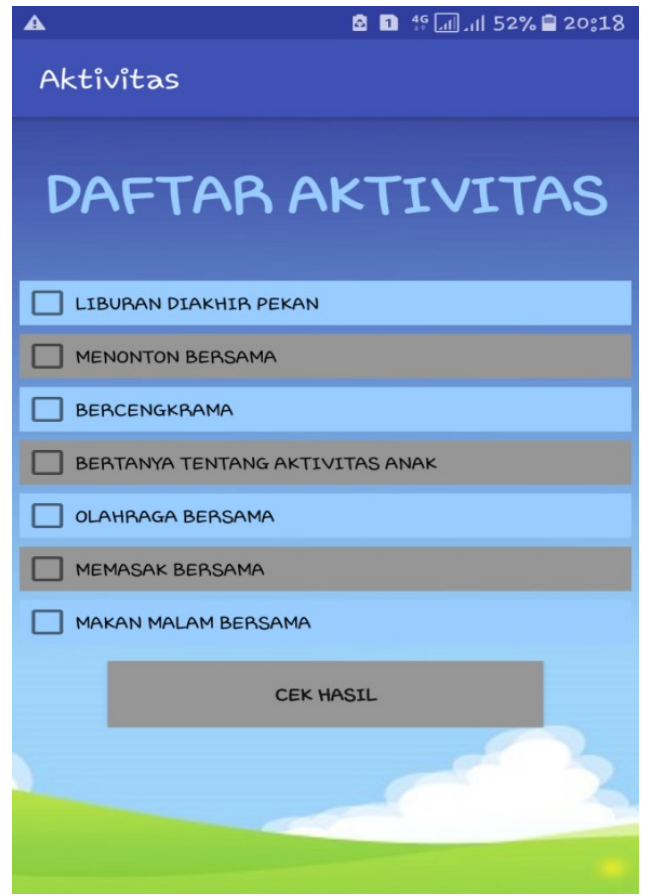

Gambar 4.9 Tampilan Menu Aktivitas

\subsubsection{Tampilan Hasil Aktivitas}

Tampilan Hasil Aktivitas ini merupakan tampilan setelah user menekan button cek hasil pada tampilan aktivitas sebelumnya.

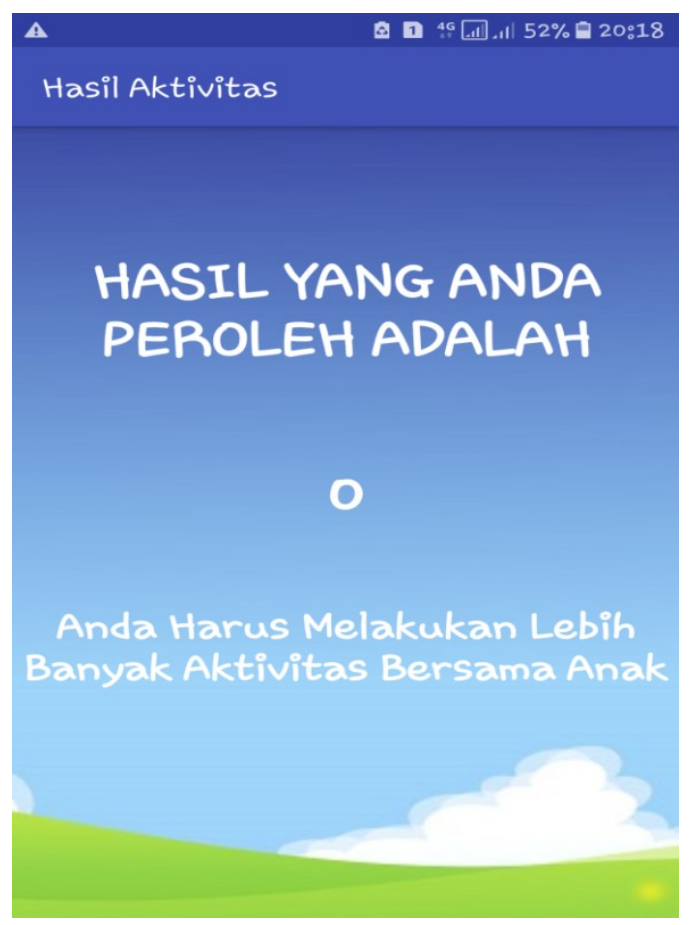

Gambar 4.10 Tampilan Hasil Aktivitas 


\subsubsection{Tampilan Menu Video}

Pada tampilan menu video ini terdapat beberapa video yang berkaitan dengan orang tua dan anak, baik video tentang kisah inspiratif, renungan maupun motivasi.

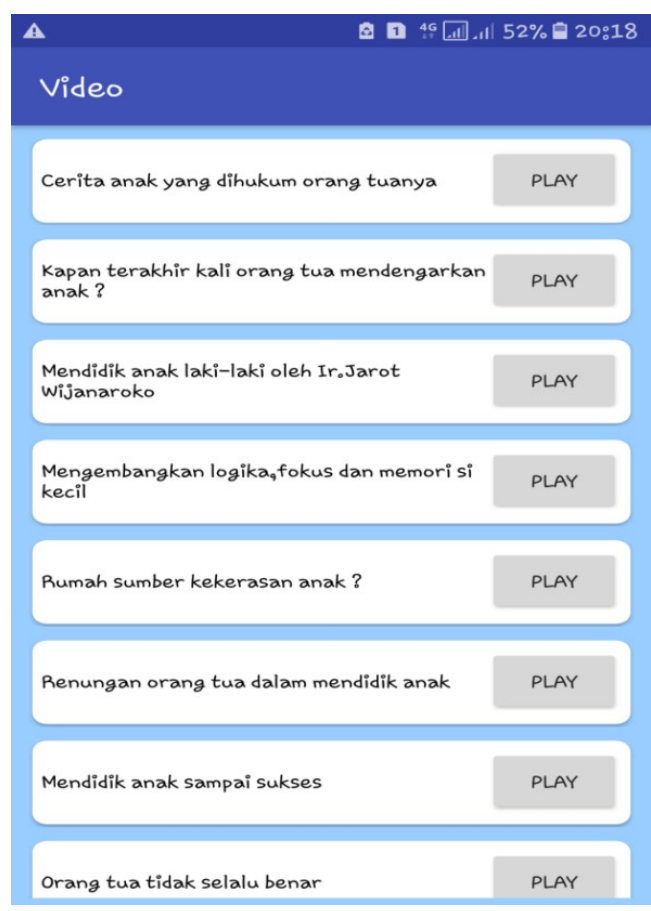

Gambar 4.11 Tampilan Menu Video

\subsubsection{Tampilan Video 1}

Tampilan ini merupakan salah satu bentuk tampilan dari Menu Video. Disini video yang akan ditampilkan adalah tentang Kisah Inspiratif.

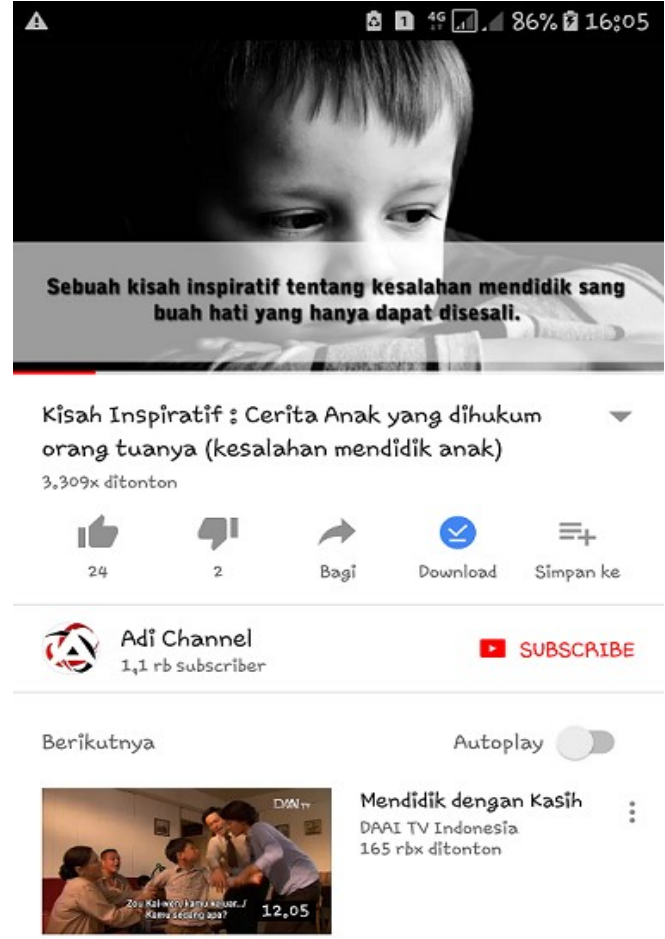

Gambar 4.12 Tampilan Video 1

\subsubsection{Tampilan Menu About}

Tampilan Menu About meupakan tampilan yang berisi penjelasan tentang aplikasi.

\section{SIMPULAN}

Dari hasil perancangan dan implementasi yang dijabarkan didalam bab-bab sebelumnya mengenai aplikasi Parenting Skills berbasis android ini, ada beberapa hal yang dapat disimpulkan oleh penulis,yaitu sebagai berikut :

1. Aplikasi Parenting Skills ini dapat dirancang dengan baik oleh penulis, sehingga dapat berguna dan menarik bagi orang tua untuk menambah pemahamannya dalam mendidik anak.

2. Aplikasi Parenting Skills ini bisa diakses di android sehingga para orang tua tidak kesulitan dalam menambah pemahamannya tentang parenting skills tersebut. 
3. Aplikasi Parenting Skills dapat diimplementasikan oleh orang tua dalam mendidik anaknya.

\section{SARAN}

Dalam menyelesaikan tugas akhir ini penulis menghadapi berbagai kendala, sehingga masih banyak kekurangankekurangan yang terdapat pada aplikasi dan laporan. Untuk itu dalam menyempurnakan program in, ada beberapa saran yang dapat penulis sampaikan yaitu sebagai berikut :

1. Aplikasi ini hanya terbatas tentang Parenting Skills saja. Mungkin dalam pengembangannya, materi dalam aplikasi ini dapat ditambah.

2. Aplikasi ini dapat dikembangkan lagi dengan memperbaiki desain menjadi lebih menarik lagi.

\section{DAFTAR PUSTAKA}

[1] Arlis, Syafri. (2016). Jurnal Teknologi Informasi \& Pendidikan VOL . 9 NO . 3 September 2016 ISSN : 2086 4981 Konsep Dasar Sistem Pengertian Sistem Karakteristik Sistem, 9(3), 59-71.

[2] A.S,Rosa \& M.Shalahuddin. 2014. Rekayasa Perangkat Lunak. Bandung : Informatika.

[3] Erica, D. (n.d.). Penerapan Parenting Pada Perkembangan Anak Usia Dini Menurut Sudut Pandang Islam.

[4] Hafizh, M. (2017). Perancangan Aplikasi Sistem Pakar Untuk Diagnosis Penyakit Infeksi Saluran Kemih dengan Metode Forward Chaining Berbasis, 4(1), 62-79.

[5] Ir. Supardi, Yuniar. (2017) Koleksi Program Tugas Akhir dan Skripsi dengan Android. Jakarta : Gramedia.

${ }^{[6]}$ Ir. Zefriyenni, MM , Arief Fuadi, S. K. (2014). Sistem Penunjang Keputusan untuk Mengukur Minat Siswa dalam Memilih Ekstrakulukuler Menggunakan Metode AHP dan didukung Oleh Software Super
Decision, 21(21), 1-7.

[7] Mallu, S. (2015). Sistem Pendukung Keputusan Penentuan Karyawan Kontrak Menjadi Karyawan Tetap Menggunakan Metode Topsis, I(2), 36-42.

[8] Mayola, Liga. (2017). Perancangan Sistem Informasi Pengolahan Data Perizinan Usaha Perdagangan Pada Kantor Badan Penanaman Modal dan Pelayanan Perizinan ( BPMP2T ) Kota Padang dengan menggunakan Bahasa Pemrograman Visual Basic.net 10.0, 4(1), 90-98.

[9] Ramadhanu, Agung. (2017). Perancangan Sistem Informasi Penjualan dan Pendistribusian Bibit Benih Ikan Pada Bbi ( Balai Benih Ikan ) Perikanan Limapuluh Kota Secara Online menggunakan Bahasa Pemograman Php dan Database MYSQL, 4(1), 1-8.

${ }^{[10]}$ Wijaya, S. W. (n.d.). Mobile Learning Sebagai Model Pembelajaran Alternatif Bagi Pemulihan Pendidikan di Daerah. 